\title{
In vitro callus induction and plantlet regeneration of sesame (Sesamum Indicum L.)
}

\author{
Muhammad Asad ${ }^{1}$, Nadeem Ahmed ${ }^{1}$, Amir Sohail ${ }^{2 *}$, Jan Sher ${ }^{3}$, Tanveer \\ Burni $^{1}$, Fazal Hadi ${ }^{1}$, Zarghoona Yousafzai ${ }^{1}$ and Salah ud Din ${ }^{1}$ \\ 1. Department of Botany, University of Peshawar, Khyber Pakhtunkhwa-Pakistan \\ 2. Key laboratory of Zhejiang Super Rice Research and State Key Laboratory of Rice Biology, China National Rice \\ Research Institute, Hangzhou-China \\ 3. Key laboratory of Tropical Plant resources and sustainable Use, Xishuangbanna Tropical Botanical Garden, \\ Chinese Academy of Science-China \\ *Corresponding author's email: amirsohail@aup.edu.pk \\ Citation \\ Muhammad Asad, Nadeem Ahmed, Amir Sohail, Jan Sher, Tanveer Burni, Fazal Hadi, Zarghoona Yousafzai and \\ Salah ud Din. In vitro callus induction and plantlet regeneration of sesame (Sesamum Indicum L.). Pure and Applied \\ Biology. Vol. 8, Issue 2, pp1307-1313. http://dx.doi.org/10.19045/bspab.2019.80073
}

\begin{tabular}{llll}
\hline \hline Received: 18/01/2019 & Revised: 08/04/2019 & Accepted: 11/04/2019 & Online First: 18/04/2019 \\
\hline \hline
\end{tabular}

\section{Abstract}

An in vitro propagation protocol was developed for Sesame (Sesamum indicum L. cv.SVPR - 1). In the present study the most important aspects of callus induction (CI) in vitro and regeneration of sesame seedlings (Sesamum indicum L.) were investigated. The explants were grown in basal medium Murashige and Skoog (MS) supplemented with different concentrations ratios of auxins and cytokines for the in vitro $\mathrm{CI}$ and the regeneration of plantlet. The callus commencement and induction was distinguished within 8 and 15 days after inoculation. Among the all combinations, 2, 4-dichlorophenoxyacetic acid (2, 4-D) and BAP with their respective concentrations of 2.0 and $0.5 \mathrm{ppm}$ were more effective for IC frequencies in all explants. The maximum number and maximum length of shoots $(11.8 \pm 0.7,9.2 \pm 0.6 \mathrm{~cm})$, the maximum number and maximum length of roots $(6.2 \pm 0.7,6.6 \pm 0.8 \mathrm{~cm})$ were well demonstrated for MS with 2.0 ppm Kinetin (Kin) and $2 \mathrm{ppm}$ indole-3-butyric acid in the explant of callus derived from the root. Seedlings with 3 to 5 shoots were transferred to pots of mixtures with equal amount of sand, soil and perlite for acclimation of field conditions and further multiplication.

Keywords: Callus induction; In vitro; Mass propagation; Sesame (Sesamum indicum L.)

\section{Introduction}

Sesamum indicum L. belongs to Pedaliaceae family and is known as an old oilseed crop and is also called the Queen of oilseeds. Sesame consists of 40 species which are grown in tropical and temperate zones [1]. They are geographically distributed in Madagascar, Tropical Australia, Tropical Africa, Pakistan, India and Afghanistan.
Almost an area of 8 million hectares is used for the growth of Sesame worldwide with a net yield of 3.3 million tons [2].

Sesame seeds are an important source of edible oil and are also used as spice. Sesame seeds by expression give a faxed oil consisting essentially of glycerides of oleic acid and linoleic acid with preparation of stearin, palmitin and myristin, solid fatty 
acids are present at approximately $12-14 \%$ of $70 \%$ liquid fatty acids It also contains potent antioxidants, lignins (sesamins), sesamolin and phytosterol, which provide a high degree of resistance to oxidative rancidity [3]. Sesame oil is used in the Ayurvedic drug system [4].

The productivity of Sesmum indicum L. is relatively low compared to other oil crops because the sesame crop is restricted by a poor soil $[5,6]$. The present investigation is carried out to develop protocols for the induction of callus and the regeneration of seedlings from explants. Current techniques along with genetic engineering can be used for the improvement of this species. In the present experiment, explants bred in vitro were tested for so-called induction, their greatest growth and their efficiency for direct regeneration. The effects of different aid in the callus, the initiation of different explants in the MS medium and the reproducible protocol have also been given for the regeneration of plants from hypocotyl explants of Sesamum indicum $\mathrm{L}$.

\section{Materials and methods}

\section{Preparation of explants}

Seeds of Sesamum Indicum L. cv. SVPR-1 for experimental work were obtained from the University of Agriculture in Peshawar. The sesame seeds were washed for 15 minutes with a tap under running water and were soaked in a $2 \%$ solution of Teepol soap for five minutes. The soaked seeds were then rinsed with distilled water repeatedly. The (seeds) of the explants were washed with 5\% sodium hypochlorite solution for 5 minutes. It is then washed with $0.01 \%$ mercury chloride solution for 2 minutes. Wash 3 times with sterile distilled water. Explants of surface sterilization have finished. Subsequently, the explants were inoculated into test tubes $(2.5 \times 15 \mathrm{~cm})$ containing nonabsorbent cotton. The cultures were allowed to retain in a dark state for duration of $48 \mathrm{~h}$ at temperature $25 \pm 2^{\circ} \mathrm{C}$ and were then exposed to a light and dark photoperiod for $16 \mathrm{~h}$ and $8 \mathrm{~h}$ respectively. The segments cut from the nodal, shoot tip and hypocotyls sections of the 8-day aseptic seedlings were used as explants.

\section{Preparation of media}

MS basal medium supplemented with $3 \%$ (w / v) sucrose and $0.8 \%(\mathrm{w} / \mathrm{v})$ agar was used for subsequent experiments. The $\mathrm{pH}$ was adjusted to 5.6 by the addition of $\mathrm{HCl}$ or $\mathrm{NaOH}$ as required. Agar was added to the boiling medium at a rate of $8 \mathrm{~g} / 1(0.8 \%)$ slowly and gradually with constant stirring to prevent clumping. After the addition of the agar medium it was placed in culture tubes. After preparation of the medium, it was sterilized in an autoclave at $121^{\circ} \mathrm{C}$ and under a pressure of 15 pounds for 15 minutes. The autoclave killed all microorganisms that were present from the beginning. Segments of hypocotyl, bud point and nodal explants were inoculated into the culture medium in $150 \mathrm{x}$ $25 \mathrm{~mm}$ test tubes containing $10 \mathrm{ml}$ of medium and covered tightly with non-absorbent cotton. Cultures containing explants were allowed to incubate at $25 \pm 2{ }^{\circ} \mathrm{C}$ for $16 / 8$ light and dark photoperiod in $30 \mu \mathrm{mol} \mathrm{m} \mathrm{m}^{-2}$ $\mathrm{s}^{1}$ cold white fluorescent tubes (Pakistan). Sub-culturing was performed at intervals of 20 days or more at the appropriate stages.

\section{In vitro callus induction}

Leaf segments of 7-day-old seedlings cultured in vitro were used as explants and placed in a callus initiation medium containing MS salts [7], vitamins B5 [8], supplemented with different concentrations of 2,4-D, NAA and IAA (0.5-3.0 ppm) alone or in combination with BAP (0.2-2.0 ppm) for the induction of callus.

\section{In vitro shoot bud proliferation from callus culture}

In vitro callus obtained from the hypocotyl explant, they were transferred to the shoot bud induction medium. The medium for the proliferation of shoots containing the combined effect of a low amount of NAA 
(0.02-0.10 ppm) and a high amount of cytokinins (Kin and BAP at 0.5-2.5 ppm) was tested for the proliferation of callus shoots.

\section{Shoots multiplication and elongation}

To obtain multiple recordings, three important steps were taken. In the first step, the individual treatment with different cytokinins (BAP and Kin) was evaluated. In the second step, at the appropriate concentration level of cytokinin for multiplication, various auxins (IBA, NAA and IAA) were evaluated at different concentrations. In the final phase, a new approach was designed for the high frequency recovery of multiple buds from leaf explants using different polyamines, amino acids, carbon sources and media supplements. The present experiment, the elongation of the induced shoots, was achieved in the same means of induction of multiple taps rather than using any other means of special extension.

Induction of root, hardening and acclimatization

The well-developed mature elongated shoots were transferred to the root induction in middle medium medium salt medium, Ganborge vitamins medium (B5) and various auxin concentrations (IAA, IBA and NAA at $0.01-0.05 \mathrm{ppm})$. When the roots were regenerated, the plants were hardened in paper cups with a 1: 1: 1 mixture of sterile soil, sand and vermiculate. The plants were kept in an environmental growth chamber for good acclimatization and were transported successfully to field.

\section{Statistical analysis}

For statistical analysis the mean values with standard errors were used for a parametric moods median test [9]. Experimental data were analyzed for variance by Duncan's multiple range test (DMRT) using the SAS programmer (SAS Institute, Cary, N.C.).

\section{Results and discussion} In vitro Callus induction
Hypocotyl explants of the in vitro elevated seedlings were used for callogenesis. The small cut segments of Hypocotyl were used as explants. Different auxins were used as medium for callus induction to culture the explants segments. Among the all auxins 2,4$\mathrm{D}$ with BAP was reported to be more effective which demonstrated the highest callus initiation of $85.8 \%$ (Table 1, Figure 1J $\& \mathrm{~N})$. Three types of auxins were used in different concentrations that produced different types of callus. Then callus was a subculture on medium with a large amount of auxin and a low amount of cytokinins. Among other types, green compact callus was best suited for regeneration than other types of callus. Auxin together with cytokinin improved the frequency of callusing. The combination of high concentrations of NAA and BAP induce green compact nature of callus, but not so in the other two combinations (Table 1). In present study 2, 4$\mathrm{D}$ with BAP in the middle concentration range demonstrated the highest percentage of organic callus induction (85\%, Table 1). Among other things, the type of auxin 2, 4-D resulted in high callus induction in (Linum usitatissimum) L. [10], in Helictere sisora L. [11] in sunflower [12] and in Dolichos lablab [13]. The high concentration of auxin $(2,4-\mathrm{D})$ is used in combination with a low concentration of cytokinin (BAP) was used for the initiation of organogenic callus in Holostemmaada-codin [14] and Malus domestica [15].

\section{Shoot bud induction from callus}

For the shoot bud induction well-developed organogenic calluses were transferred on to shoot bud induction medium. Bud induction medium containing different concentrations of cytokinins (BAP, TDZ and Kin) along with lower concentrations of auxin NAA were used (Table 2). Adventitious buds regenerated from the organogeniccalli occurred after 30 days and regeneration of multiple shoots from the adventitious buds 
occurred in the next two subculture multi number of shoots was produced in organogenic callus derived from the hypocotyl explant (28.4 shoots/callus) (Table 2; Figure 1L). Regeneration from callus is reported from young leaves in Linum [10, 16] leaf segment in caster [17] and hypocotyl segments of in sesame [18].

Effect of cytokinin (BAP, TDZ and Kin) along with NAA

In the current study, a different concentration of BAP, TDZ and Kin with NAA was used for multiple shoot induction (Table 3). Maximum percentage of response $(90.8 \%)$ occurred at BAP (2.0 ppm) with NAA (0.04 ppm). Multiple shoots exhibited the highest regeneration frequency in BAP with NAA combination followed by TDZ with NAA combination. Several cytokinins in combination with auxin are known to exhibit high levels of shoot formation in Linum [19, $20]$ and in sesame [21, 22].

\section{Elongation, rooting and hardening}

In vitro regenerated multiple shoots of hypocotyl-derived callus were transferred to MS medium enriched with GA3. The maximal percentage response was recorded in $0.6 \mathrm{ppm}$ GA3 supplemented medium (Figure $1 \mathrm{~m} \& \mathrm{n}$ ). Prolonged shoots were transferred to root media enriched with various auxins (IBA, NAA and IAA), of the different concentration at which NAA $(0.03 \mathrm{ppm})$ produced the maximum number of roots (Table 3). Rooted plants were transferred to paper cups and kept in an environmental plant growth chamber for hardening. When the curing process was complete, the plants were transferred to earthen pots and then transferred to the field state. In vitro regenerated plants showed $77 \%$ survival rate under greenhouse effect. Therefore, the results obtained here could be useful for mass distribution of this plant. Such results were observed by [10, 23-25].

Table 1. Effect of different concentration of auxins along with cytokinin on Callus Induction from hypocotyl

\begin{tabular}{|c|c|c|}
\hline $\begin{array}{c}\text { Plant Growth } \\
\text { Regulators }(\mathrm{mg} / \mathrm{l})\end{array}$ & $\begin{array}{c}\text { \% of callus } \\
\text { Induction }\end{array}$ & $\begin{array}{c}\text { Nature and type } \\
\text { of callus }\end{array}$ \\
\hline NAA + BAP & $64.5+2.54$ & Yellowish Green Friable \\
$1.0+0.2$ & $70.4+3.12$ & Yellowish Friable \\
$2.0+0.4$ & $72.1+3.01$ & Green Friable \\
$3.0+0.6$ & $56.9+1.96$ & Green Compact \\
$4.0+0.8$ & $62.5+1.65$ & Green Compact; \\
$5.0+1.0$ & & \\
& & \\
IAA + BAP & $51.6+3.4$ & Yellowish Brown Compact \\
$1.0+0.2$ & $58.5+2.78$ & Green Friable \\
$2.0+0.4$ & $75.2+2.57$ & Green Friable \\
$3.0+0.6$ & $65.2+1.59$ & Yellowish Friable \\
$4.0+0.8$ & $50.5+1.85$ & Green Friable \\
$5.0+1.0$ & & \\
& & Yellowish Friable \\
$\mathbf{2} \mathbf{4}+\mathbf{B A P}$ & $56.6+1.65$ & Green Compact \\
$1.0+0.2$ & $74.6+2.21$ & Green Friable \\
$2.0+0.4$ & $\mathbf{8 5 . 8}+\mathbf{3 . 6 1}$ & Green Friable \\
$\mathbf{3 . 0}+\mathbf{0 . 6}$ & $63.4+2.95$ & Yellowish Brown Compact \\
$4.0+0.8$ & $65.1+1.47$ & \\
$5.0+1.0$ &
\end{tabular}

20-explants tested, values are means $+\mathrm{SE}$ of replication of 5 replication of 5 repeated experiments 
Table 2. Effect of different concentration of cytokinin along with NAA on shoot bud Induction from callus

\begin{tabular}{|c|c|c|c|}
\hline $\begin{array}{c}\text { Plant Growth } \\
\text { Regulators (mg/l) }\end{array}$ & $\begin{array}{c}\text { \% of shoot bud } \\
\text { response }\end{array}$ & $\begin{array}{c}\text { Mean number of } \\
\text { shoots }\end{array}$ & $\begin{array}{c}\text { Mean number of } \\
\text { nodes / shoot }\end{array}$ \\
\hline TDZ + NAA & $49.5+0.56$ & $2.5+0.10$ & $14.6+0.2$ \\
$0.5+0.4$ & $53.7+0.58$ & $3.9+0.12$ & $13.8+0.22$ \\
$1.0+0.4$ & $55.8+0.49$ & $3.4+0.12$ & $10.5+0.19$ \\
$1.5+0.4$ & $84.3+0.50$ & $3.6+0.15$ & $21.9+0.17$ \\
$2.0+0.4$ & $70.1+0.45$ & $1.9+0.09$ & $18.4+0.14$ \\
$2.5+0.4$ & & & \\
BAP + NAA & $60.3+0.59$ & $3.5+0.11$ & $20.0+0.25$ \\
$0.5+0.4$ & $75.8+0.65$ & $3.9+0.14$ & $22.4+0.22$ \\
$1.0+0.4$ & $88.4+0.67$ & $4.1+0.13$ & $24.8+0.19$ \\
$1.5+0.4$ & $90.8+0.83$ & $4.5+0.16$ & $19.5+0.18$ \\
$2.0+0.4$ & $80.7+0.72$ & $4.0+0.15$ & \\
$2.5+0.4$ & & & $10.9+0.09$ \\
Kin + NAA & & & $11.5+0.10$ \\
$0.5+0.4$ & $51.2+0.28$ & $2.8+0.11$ & $13.4+0.07$ \\
$1.0+0.4$ & $55.6+0.29$ & $4.0+0.12$ & $15.7+0.09$ \\
$1.5+0.4$ & $61.2+0.33$ & $3.9+0.10$ & \\
$2.0+0.4$ & $71.2+0.39$ & $3.5+0.14$ & \\
$2.5+0.4$ & $49.6+0.25$ & $2.9+0.07$ & \\
\hline
\end{tabular}

20-explants tested, values are means + SE of replication of 5 replication of 5 repeated experiments

Table 3. Effect of different concentration of auxins on root induction on elongated shoots

\begin{tabular}{|c|c|c|c|c|}
\hline $\begin{array}{l}\text { Con. of auxins } \\
(\mathbf{m g} / \mathbf{l})\end{array}$ & $\begin{array}{l}\text { N0. of roots } \\
(\text { Mean }+ \text { SE) }\end{array}$ & $\begin{array}{c}\text { \% of roots Response }(\mathrm{cm}) \\
(\text { Mean }+ \text { SE })\end{array}$ & $\begin{array}{l}\text { Length of roots }(\mathrm{cm}) \\
(\text { Mean }+ \text { SE) }\end{array}$ & $\begin{array}{c}\text { Callus } \\
\text { formation }\end{array}$ \\
\hline \begin{tabular}{l|} 
IAA \\
0.01 \\
0.02 \\
$\mathbf{0 . 0 3}$ \\
0.04 \\
0.05
\end{tabular} & $\begin{array}{l}4.0+0.15 \\
4.8+0.14 \\
\mathbf{5 . 6}+\mathbf{0 . 1 9} \\
5.2+0.10 \\
3.8+0.12\end{array}$ & $\begin{array}{l}62.2+3.5 \\
82.9+4.0 \\
\mathbf{9 1 . 8}+4.7 \\
75.2+4.0 \\
60.4+3.9\end{array}$ & $\begin{array}{l}09.1+0.54 \\
10.0+0.51 \\
\mathbf{1 2 . 4}+\mathbf{0 . 6 5} \\
09.8+0.48 \\
08.5+0.43\end{array}$ & $\begin{array}{c}- \\
++ \\
- \\
- \\
+\end{array}$ \\
\hline $\begin{array}{c}\text { NAA } \\
0.01 \\
0.02 \\
0.03 \\
0.04 \\
0.05\end{array}$ & $\begin{array}{l}2.9+0.05 \\
2.7+0.04 \\
3.0+0.15 \\
3.8+0.11 \\
3.4+0.13\end{array}$ & $\begin{array}{l}48.9+2.8 \\
50.1+3.5 \\
55.6+3.8 \\
48.9+4.1 \\
47.2+2.9\end{array}$ & $\begin{array}{l}05.2+0.36 \\
07.5+0.31 \\
10.2+0.46 \\
08.5+0.39 \\
06.3+0.34\end{array}$ & $\begin{array}{c}- \\
- \\
+ \\
++ \\
-\end{array}$ \\
\hline $\begin{array}{l}\text { IBA } \\
0.01 \\
0.02 \\
0.03 \\
0.04 \\
0.05\end{array}$ & $\begin{array}{l}2.7+0.16 \\
3.0+0.12 \\
2.5+0.11 \\
1.9+0.10 \\
1.7+0.07\end{array}$ & $\begin{array}{l}45.8+2.5 \\
50.9+2.7 \\
49.7+2.4 \\
46.5+2.1 \\
34.1+1.9\end{array}$ & $\begin{array}{l}05.3+0.21 \\
06.2+0.28 \\
09.8+0.30 \\
04.3+0.25 \\
05.4+0.20\end{array}$ & $\begin{array}{c}- \\
- \\
- \\
++ \\
+\end{array}$ \\
\hline
\end{tabular}

20-explants tested, values are means + SE of replication of 5 replication of 5 repeated experiments 

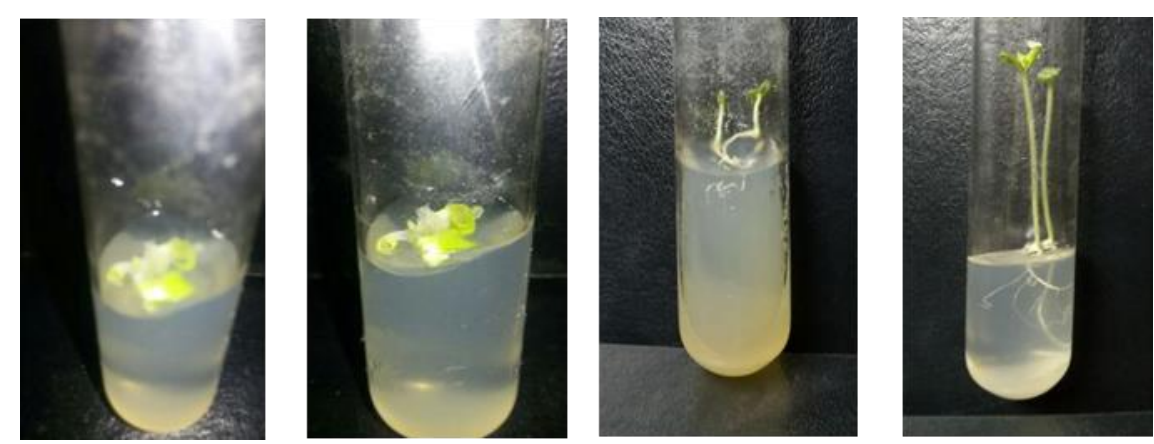

Figure 1. Different In vitro developmental stages of Sesamum indicum $\mathrm{L}$

$\mathbf{J}$ - Callus induction; $\mathbf{L}$ - initiation of callus; $\mathbf{M}$ - initiation of shoot; $\mathbf{N}$ - elongation of shoot

\section{Conclusion}

In vitro culture of plants has gained importance during recent years because this technique can be used for the rapid multiplication and ex-situ conservation of some plants. The aim of the present work was to determine the culture conditions for micro propagation of this plant. The present study discovers nodal segment as effective explants which expressed maximum shoot induction in MS medium with different concentration of PGRs. Further this study showed that the high frequency organogenesis occurs by using BAP, IBA and IAA is possible. It could be used as a tool to protect the biodiversity/natural vegetation of S.indicum L.

\section{Authors' contributions}

Conceived and designed the experiments: $\mathrm{N}$ Ahmad, Performed the experiments: M Asad, Analyzed the data: A Sohail, R Ali \& T Burni, Contributed reagents/ materials/ analysis tools: J Sher F Hadi, Z Yousafzai \& S U Din, Wrote the paper: M Asad \& A Sohail.

\section{References}

1. Osawa $T$, Kumon $H$, Namiki $M$, Kawakishi S \& Fukuda Y (1990). Antimutagenic heat stable antioxidants, in Mutagens and Carcinogens in the Diet. Edited by M. W. Pariza, H.-U. Aeschbacher, JS Felton and S Sato, pp 223-238.
2. FAOSTAT (2008). http://faostat.fao.org.

3. Brar GS \& Ahuja KL (1979). Sesame: its culture, genetics, breeding and biochemistry. In: CP Malik (ed.). Annual Review Plant Science, Kalyani Publishers, New Delhi. 245-313.

4. Michael Murray ND, Joseph Pizzorno ND \& Lara Pizzorno (2005). The Encyclopedia of Healing Foods. Publisher: Atria, 1st Edition.

5. George L, Bapat VA \& Rao PS (1987). In vitro multiplication of sesame (Sesamum indicum) through tissue culture. Ann Bot 60: 17-21.

6. Evans DA, Sharp WR \& Bravo JE (1984). Cell culture methods for crop improvement. In: In Handbook of plant cell culture: crop species. Eds. WR Sharp, DA Evans, PVA mmirato and Yamada, Y Macmillan Publishing Co, New York, pp 47-68.

7. Murashige T \& Skoog F (1962). A revised medium for rapid growth and bioassays with tobacco tissue cultures. Plant Physiol 15:473-497.

8. Gamborg OL, Miller RA \& Ojima K (1968). Nutrient requirements of suspension culture of soybean root cells. Exp Cell Res 50: 151-158.

9. Snedecor GW \& Cochran WG (1989). Statistical methods, 8th edition. Lowa State University Press, Ames. 
10. Burbulis N, Blinstrubiene A, Sliesaravicius A \& Kupriene R (2007). Some factors affectingcallus induction in ovary culture of flax (Linum usitatissimum L.). Biologia 53: 21-23.

11. Shriram V, Kumar V \& Mahadeo SG (2008). Indirect organogenesis and plant regeneration in Helicteres isora L., an important medicinal plant. In vitro Cell Dev Biol Plant 44: 186-193.

12. Gregco B, Tanzarella A, Carrozzo G \& Blanco A (1984). Callus induction and shoot regeneration in sunflower (Helianthus annuus L.) Plant Sci 36: 73 77.

13. Sounder RV, Nijalingappa BHM \& Tejavathi DH (1991). In vitro studies in Dolichos lablab var. Lignosus, (L.) Prain. Ind J Exp Biol 29: 221-225.

14. Martin KP (2002). Rapid propagation of Holostemma ada-kodien Schult, a rare medicinal plant, through axillary bud multiplication and indirect organogenesis. Plant Cell Rep 21: 112117.

15. Caboni E, Lauri P \& Angell SD (2000). In vitro plant regeneration from callers of shoot apices in apple shoot culture, Plant cell Rep 19: 755-760.

16. Yildiz M, Sağlik C, Kahramanoğullari CT \& Erkiliç EG (2011). The effect of in vitro competition on shoot regeneration from hypocotyl explants of Linum usitatissimum. Turkish J Bot 35(2): 211218.

17. Reddy, KRK \& Bahadur B (1989). In vitro multiplication of castor. In: Farook SA, Khan IA, editors. Recent Advances in Genetics and Cytogenetics. Hyderabad: Premier, pp 479-82.

18. Lokesha R, Shashidhara N \& Janagoudar BS (2007). Callus induction and plant regeneration in Sesame (Sesamum indicum L.) through direct seeding. Plant cell Biotech Mol Bio 8(1\&2): 85-88.

19. Zhan XC, Jones DA \& Keer A (1989b) In vitro plantlet formation in Linum marginale from cotyledons, hypocotyls, leaves, roots and protoplasts. Aust J Pl Physiol 16: 315-320.

20. Janowicz J \& Wojciechowski A (2009). The evaluation of regeneration ability of two flax (Linum usitatissimum L.) cultivars in in vitro culture. Oilseed Crops 30(1): 35-50.

21. Rao KR \& Vaidyanath K (1997). Induction of multiple shoots from seedling shoot tips of different varieties of Sesamum. Indian J Pl Physiol 2: 257261.

22. Younghee K (2001). Effects of BA, NAA, 2, 4-D and AgNO3 treatments on the callus induction and shoot regeneration from hypocotyl and cotyledon of sesame (Sesamum indicum L.). J of the Korean Soc for Horticul Sci 42: 70-74.

23. Niedz'WSI \& Giersimiuk A (2001) Environmental factors affecting the cyanogenic potential of flax seedlings. Acta Physiol Plant 23: 383-390.

24. Baskaran P \& Jayabalan N (2003). Effect of growth regulators on multiple shoot productin in Sesamum indicum L. Indian J Plant Physiol 2: 639-642.

25. Seo HY, Kim YJ, Park TI, Kim HS, Yun SJ, Park KH, Oh MK, Choi MY, Paik CH, Lee YS \& Choi YE (2007). Highfrequency plant regeneration via adventitious shoot formation from deembryonated cotyledon explants of Sesamum indicum L. In vitro Cell Dev Biol 43: 209-214. 